\title{
Multilayer perceptron neural network for downscaling rainfall in arid region: A case study of Baluchistan, Pakistan
}

\author{
Kamal Ahmed ${ }^{1}$, Shamsuddin Shahid ${ }^{1, *}$, Sobri Bin Haroon ${ }^{1}$ and Wang XiaO-Jun ${ }^{2,3}$ \\ ${ }^{1}$ Department of Civil Engineering, Universiti Teknologi Malaysia, Johor Bahru, Malaysia. \\ ${ }^{2}$ State Key Laboratory of Hydrology-Water Resources and Hydraulic Engineering, Nanjing Hydraulic Research \\ Institute, Nanjing, China. \\ ${ }^{3}$ Research Center for Climate Change, Ministry of Water Resources, Nanjing, China. \\ *Corresponding author.e-mail: sshahid@utm.my
}

\begin{abstract}
Downscaling rainfall in an arid region is much challenging compared to wet region due to erratic and infrequent behaviour of rainfall in the arid region. The complexity is further aggregated due to scarcity of data in such regions. A multilayer perceptron (MLP) neural network has been proposed in the present study for the downscaling of rainfall in the data scarce arid region of Baluchistan province of Pakistan, which is considered as one of the most vulnerable areas of Pakistan to climate change. The National Center for Environmental Prediction (NCEP) reanalysis datasets from 20 grid points surrounding the study area were used to select the predictors using principal component analysis. Monthly rainfall data for the time periods 1961-1990 and 1991-2001 were used for the calibration and validation of the MLP model, respectively. The performance of the model was assessed using various statistics including mean, variance, quartiles, root mean square error (RMSE), mean bias error (MBE), coefficient of determination $\left(\mathrm{R}^{2}\right)$ and Nash-Sutcliffe efficiency (NSE). Comparisons of mean monthly time series of observed and downscaled rainfall showed good agreement during both calibration and validation periods, while the downscaling model was found to underpredict rainfall variance in both periods. Other statistical parameters also revealed good agreement between observed and downscaled rainfall during both calibration and validation periods in most of the stations.
\end{abstract}

\section{Introduction}

There is wide agreement in the international scientific society that climate change will cause sharp increase in temperature, which in turn is likely to affect evapotranspiration and atmospheric water storage, thereby potentially changing the magnitudes, frequencies and intensities of rainfall as well as its seasonal and inter-annual variabilities (Middelkoop et al. 2001; Chen and Xu 2005; Akhtar et al. 2008; Zhang et al. 2008; Wang et al. 2013; Wang et al. 2014). Small changes in the mean and standard deviation values can produce relatively large changes in the probability of extreme events (Groisman et al. 1999; Rodrigo 2002; Chiew 2006; Su et al. 2006; Shahid 2011; Pour et al. 2014). Regions with arid and semi-arid climates are more sensitive even to insignificant changes in climatic characteristics (Lins et al. 1990; Mehrotra and Mehrotra 1995; Samadi et al. 2012). Therefore, such changes in climatic variables will have a significant impact on local hydrological regimes in the arid and semi-arid regions (Samadi et al. 2013). Understanding and modelling the potential

Keywords. Multilayer perceptron neural network; rainfall; arid region; downscaling. 
impacts of climate in an arid region under the current and future climate is therefore very essential (Huth et al. 2008).

General circulation models (GCMs) and Earth system models (ESMs) are considered as the most important and appropriate tools for modelling and assessing the impact of climate change (Chu et al. 2010; Goyal and Ojha 2012). The raw outputs of climate change simulation from GCMs, however, fails to provide reliable information on spatial scales below about $200 \mathrm{~km}$ and also to resolve significant subgrid scale features such as, topography, clouds, land use, complex and sharp orography (Maraun et al. 2010; Goyal et al. 2012). Downscaling of GCM output at the local scale is therefore used to overcome this problem. The primary purpose of downscaling is to transfer largescale atmospheric variables into regional or local scale (Wetterhall et al. 2006). A number of downscaling methods have been developed in the past two decades, which can be classified into two categories, i.e., dynamical and statistical downscaling. Among these two classes, statistical downscaling methods are widely used for their simplicity, easiness, flexibility, quickness and ability to provide local-scale information. Among the statistical downscaling methods, regression models, which are used to quantify the direct relationships between the predictands and predictor variables, are the most popular methods (Guo et al. 2012).

Several regression-based statistical methods have been developed and applied, such as, principal component analysis, artificial neural networks, multiple linear regression, and canonical correlation analysis (Mahmood and Babel 2013). However, the relationship between predictor and predictand is often very complex in nature, and linear regression based methods cannot work very well (Goyal and Ojha 2012; Ahmadi et al. 2014). This is especially true for an arid region, where the relation between local rainfall and ocean-atmospheric circulation parameters are not explicitly understood. Rainfall in an arid region is very erratic and infrequent. Sufficient data and information are also not often available for analysis. These have made the downscaling of rainfall in an arid region much challenging (Maurer and Hidalgo 2008).

To model the complex relationship between predictor and predictand, a number of non-linear regression-based downscaling models have been introduced (Haylock et al. 2006; Harpham and Dawson 2006; Cannon 2008; Hashmi et al. 2011). Recent studies showed that statistical downscaling based on artificial neural network (ANN) models can present good non-linear regression models (Mendes and Marengo 2010; Hashmi et al. 2011; Goyal and Ojha 2012; Gaitan et al. 2014). In the present study, an artificial neural network known as
Multilayer Perceptron (MLP) neural network has been used for downscaling rainfall. Multilayer perceptron is the most popular, flexible and simplest type of artificial neural network and has been used successfully for climate downscaling in various climatic regions (Harpham and Dawson 2006; Cannon 2008; Pour et al. 2014).

The literature review revealed that only a few studies have been conducted for downscaling rainfall in the arid regions such as, the studies by Şen et al. (2012) in the Riyadh City of Saudi Arabia, Goyal et al. (2011), Anandhi et al. (2008) in the upstream of Malaprabha reservoir in India, Souvignet and Heinrich (2011) in Coquimbo Region of Chile, Samadi et al. (2013) in western Iran, and Liu et al. (2011) in Tarim River basin in China. However, there is still a need to model and assess the impacts of climate change in arid regions located in other parts of the world.

Baluchistan, an arid province of Pakistan is selected as the study area in the present study. Pakistan is one of the most vulnerable countries in the world to climate change. Climate projections indicated that average temperate in the country will rise 1.1 to $6.4^{\circ} \mathrm{C}$ by the end of the current century (Syed et al. 2014). Baluchistan, the arid province of Pakistan is considered to be a more vulnerable region of Pakistan. It is anticipated that droughts and water scarcity will continuously increase in the region throughout the 21st century, which will severely affect the economy and livelihood of the people, if adaptation measures are not taken. Despite high vulnerability to climate change, little attention has been paid so far to understand the possible future changes in climate and their impacts in Baluchistan. The review of the literature revealed that no studies on climate change projection at the local scale have been conducted in the region. Some studies in the upper parts of Pakistan have been conducted, such as Mahmood and Babel (2013) downscale, the precipitation over Jhelum river basin using SDSM, Akhtar et al. (2008) studied the impacts of climate change over three river basins in Pakistan by using PRECIS, Ashiq et al. (2010) downscaled the precipitation in the northwestern Himalayan mountains and upper Indus plains of Pakistan by using PRECIS, Syed et al. (2014) conducted study over Karakoram and the Hindu-Kush mountain ranges that stretches between central Afghanistan and northern Pakistan by using PRECIS. It is expected that the present study will help in downscaling climate, which in turn will help in future climate projections for necessary mitigation and adaptation planning in arid regions.

The rest of this paper is structured as follows: Section 2 describes the general features, climate of the study area, and the dataset used in the study, 
section 3 describes the methodology used for the study, section 4 discusses the obtained results, and finally section 5 gives the conclusions based on the obtained results.

\section{Study area}

Baluchistan is a mountainous, desert and an arid province, located between $30.12^{\circ} \mathrm{N}$ and $67.01^{\circ} \mathrm{E}$ of Pakistan. The location of Baluchistan province of Pakistan is shown in figure 1. Physically, it is an extensive plateau of rough terrain divided into basins by ranges of sufficient heights and ruggedness. Geographically, it is divided into four distinct zones: upper highlands, lower highlands, plains, and deserts. The topography of the study area, shown in figure 1, reveals a large variation over a short distance. The high variability in topography strongly influences the climate. Mountains primarily dominate the terrain in the region. The climate of the province lies in the region of hyper-arid, arid and semi-arid, as shown in figure 2 (a).

The rainfall is scanty and unevenly distributed. Spatial distribution of mean annual rainfall in the study area is shown in figure 2(b). The area is predominantly arid and receives rainfall which varies from $30 \mathrm{~mm}$ in the northwest desert to $397 \mathrm{~mm}$ in the northeast (Ahmed et al. 2014). The amount of rainfall varies over time and space in different seasons.
Monsoon winds and the western depression are the main sources of rainfall during summer and winter, respectively in the area. About $58 \%$ of total rainfall in the area occurs during winter caused by western depression. On the other hand, $31 \%$ of the total rainfall in the area happens during monsoon. Winter rainfall (December-March) is caused by western depressions that originate in the Mediterranean Sea. On the other hand, monsoon winds bring moist air from Bay of Bengal during the months of June to September. The monsoon wind enters the area from the southeast corner of the province and, therefore, southeastern part of the province receives more rainfall during monsoon. As the monsoon progresses through the land, air moisture content reduces, and the amount of monsoon rainfall gradually decreases from the east to the west.

\subsection{Data and sources}

Data from 14 meteorological stations (figure 1) were collected in order to use as the predictor in the downscaling model. The major challenge of hydrological study in the province is the missing rainfall data. The percentage of missing rainfall data in the study area was found to vary between 0 and $33.13 \%$ (table 1). The missing values were computed using expectation-maximization (EM) method. The EM algorithm iteratively computes the maximum likelihood estimates to increase the relationship between the missing value and the

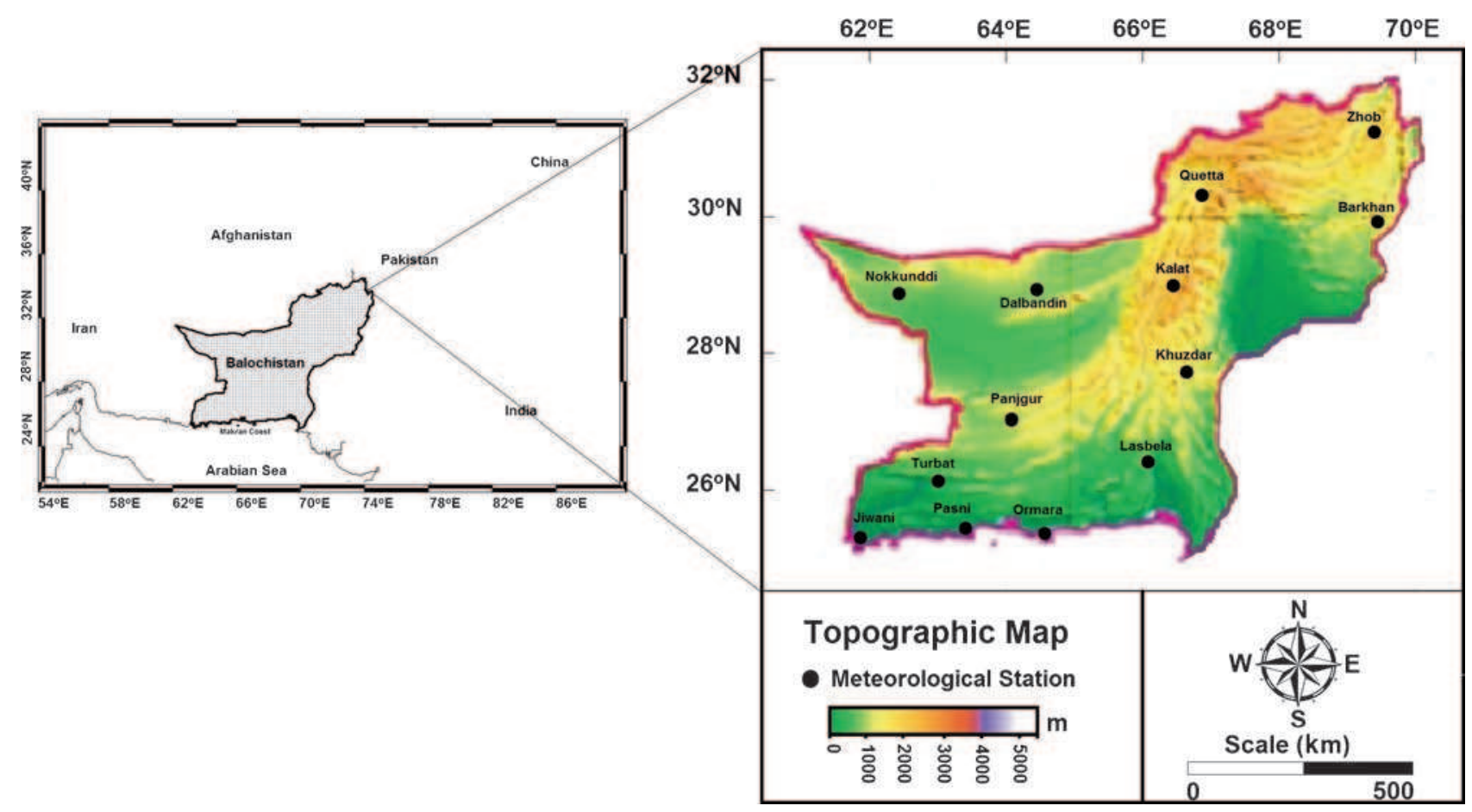

Figure 1. Geographical location and topography of Baluchistan province of Pakistan. 

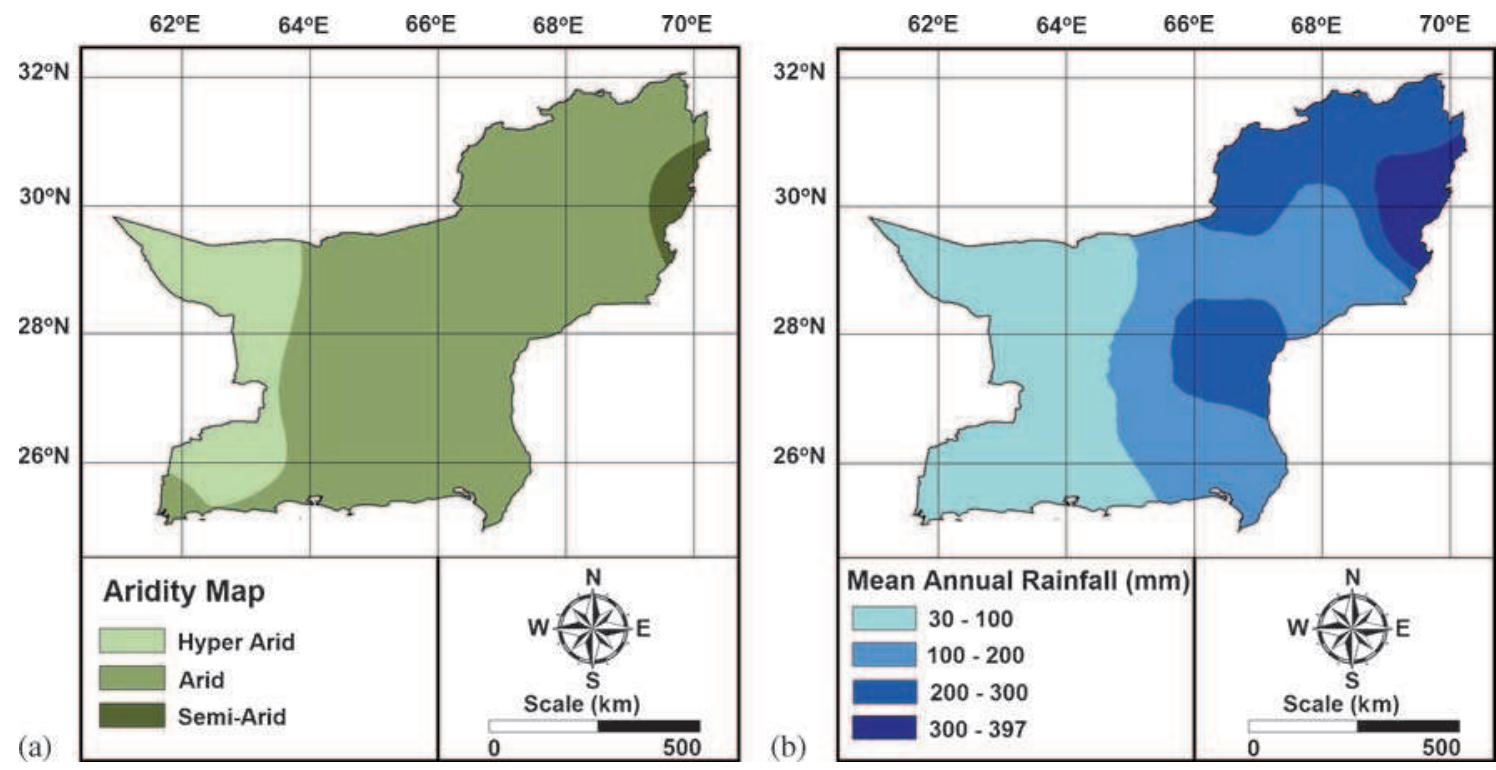

Figure 2. (a) Aridity and (b) mean annual rainfall in Baluchistan.

Table 1. Percentage of missing data and result of homogeneity test.

\begin{tabular}{lcc}
\hline Station name & $\begin{array}{c}\text { Missing } \\
\text { data }(\%)\end{array}$ & $\begin{array}{c}\text { Standard normal } \\
\text { homogeneity } \\
\text { test (SNHT) }\end{array}$ \\
\hline Barkhan & 1.22 & $\mathrm{H}_{0}$ \\
Dalbandin & 0.00 & $\mathrm{H}_{0}$ \\
Jiwani & 0.41 & $\mathrm{H}_{0}$ \\
Kalat & 8.94 & $\mathrm{H}_{0}$ \\
Khuzdar & 0.20 & $\mathrm{H}_{0}$ \\
Lasbela & 0.00 & $\mathrm{H}_{0}$ \\
Nokkunddi & 0.81 & $\mathrm{H}_{0}$ \\
Ormara & 33.13 & $\mathbf{H}_{\mathbf{a}}$ \\
Panjgur & 0.20 & $\mathrm{H}_{0}$ \\
Pasni & 7.93 & $\mathrm{H}_{0}$ \\
Quetta & 0.00 & $\mathrm{H}_{0}$ \\
Sibbi & 2.64 & $\mathrm{H}_{0}$ \\
Turbat & 2.44 & $\mathrm{H}_{0}$ \\
Zhob & 0.00 & $\mathrm{H}_{0}$ \\
\hline
\end{tabular}

unknown parameters of a data model. It iteratively computes the maximum likelihood estimates to increase the relationship between the missing value and the unknown parameters of a data model. The EM algorithm mainly consists of two main steps; conditional expectation E-step and maximization M-step. The E-step attempts to create a function for the expectation of the log-likelihood, evaluated using the current estimate for the parameters. The M-step computes parameters maximizing the expected log-likelihood found on the E-step. These parameter-estimates are then used to determine the distribution of the latent variables in the next E-step. The parameters are then re-estimated, and so on, proceeding iteratively until convergence (Ng and McLachlan 2004). A full descript of EM algorithm can be found in McLachlan and Krishnan (1997). EM has been widely used in recent years for computation of missing rainfall data (Firat et al. 2010; Tsidu 2012; Alamgir et al. 2015).

The accuracy of downscaling model often requires long-term reliable and continuous precipitation data. It is also expected that the data should be homogeneous (Kajornrit et al. 2012). The homogeneity of rainfall data in the study area was assessed using standard normal homogeneity test (SNHT) (Alexandersson 1986). SNHT is widely used for detecting inhomogeneity in rainfall data (Santos and Fragoso 2013; Hosseinzadeh Talaee et al. 2014). SNHT was applied at each station separately to detect the inhomogeneity at a confidence level of $95 \%$ with null hypothesis $\left(\mathrm{H}_{0}\right)$ : data are homogeneous and alternative hypothesis $\left(\mathrm{H}_{\mathrm{a}}\right)$ : there is a month at which there is a change in the data. The obtained result is given in table 1.

The results revealed homogeneity in rainfall time series in all stations except at Ormara, where the percentage of missing data is also very high. Therefore, Ormara station was discarded from the study.

Twenty-six large-scale atmospheric reanalysis (National Center for Environmental Prediction (NCEP)) variables listed in table 2 , which are used as the proxy of current observation of GCM variables were collected from the website of the Canadian Climate Change Scenarios Network (CCCSN) and used as predictors in downscaling model.

There are no general guidelines for the selection of predictors. Choice of predictors varies from one region to another, and mainly depends on the 
Table 2. List of NCEP variables used to select predictors for downscaling rainfall.

\begin{tabular}{cll}
\hline No. & Variables & \multicolumn{1}{c}{ Description } \\
\hline 1 & mslp & Mean sea level pressure \\
2 & p_f & Surface airflow strength \\
3 & p_u & Surface zonal velocity \\
4 & p_v & Surface meridional velocity \\
5 & p_z & Surface vorticity \\
6 & p_th & Surface wind direction \\
7 & p_zh & Surface divergence \\
8 & p5_f & $500 \mathrm{hPa}$ airflow strength \\
9 & p5_u & $500 \mathrm{hPa}$ zonal velocity \\
10 & p5_v & $500 \mathrm{hPa}$ meridional velocity \\
11 & p5_z & $500 \mathrm{hPa}$ vorticity \\
12 & p500 & $500 \mathrm{hPa}$ geopotential height \\
13 & p5th & $500 \mathrm{hPa}$ wind direction \\
14 & p5zh & $500 \mathrm{hPa}$ divergence \\
15 & p8_f & 850 hPa airflow strength \\
16 & p8_u & 850 hPa zonal velocity \\
17 & p8_v & 850 hPa meridional velocity \\
18 & p8_z & 850 hPa vorticity \\
19 & p800 & 850 hPa geopotential height \\
20 & p8th & $850 \mathrm{hPa}$ wind direction \\
21 & p8zh & $850 \mathrm{hPa}$ divergence \\
22 & rhum & Near surface relative humidity \\
23 & r500 & Relative humidity at 500 hPa \\
24 & r850 & Relative humidity at $850 \mathrm{hPa}$ \\
25 & shum & Near surface specific humidity \\
26 & temp & Mean temperature \\
\hline & &
\end{tabular}

characteristics of large-scale atmospheric circulation, seasonality, regional topography, and the predictand to be downscaled (Tripathi et al. 2006; Anandhi et al. 2008). The aerial extent of the climatic domain for the selection of predictors is usually selected based on the mechanism of rainfall in an area (Kannan and Ghosh 2011). Therefore, it is very crucial to select an adequate size of the domain. According to Najafi et al. (2010), the domain size neither should be too small, that may not capture atmospheric phenomena nor too large to increase the computation of cost and time. Therefore, a domain consisting of 20 grid points covering the region between latitudes $22.5^{\circ}-32.5^{\circ} \mathrm{N}$ and longitudes $60^{\circ}-71.25^{\circ} \mathrm{E}$ (figure 3 ) were selected, considering that the domain is sufficient to cover the influence of circulation patterns of precipitation climate of the study area.

\section{Methodology}

\subsection{Multilayer perceptron neural network}

Multilayer perceptron (MLP) is the most popular, flexible and the simplest type of artificial neural network. The method is widely used to map the nonlinear relationship between predictor and predictands (Dawson and Wilby 2001; Chadwick et al. 2011). The main task of the neural network is to improve the performance function between

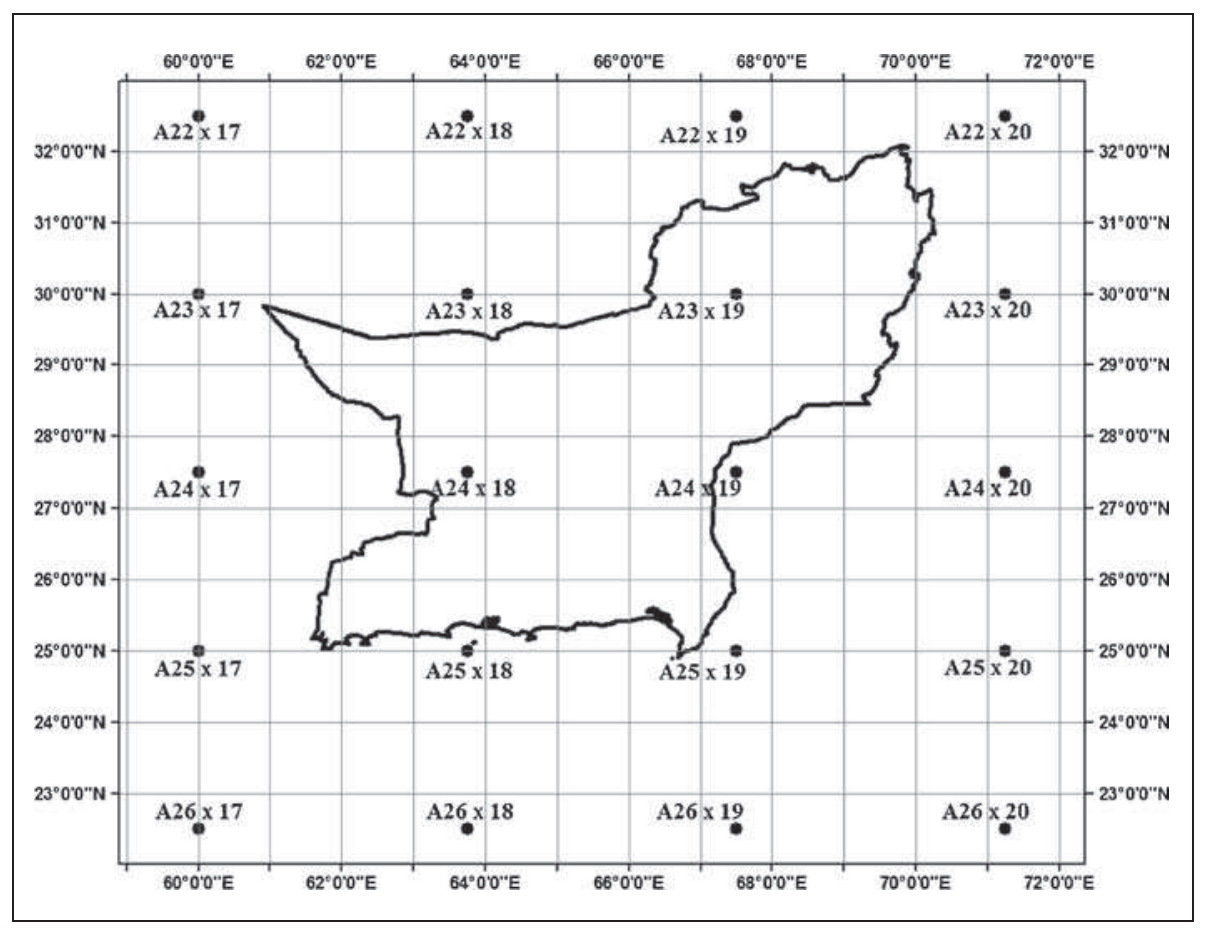

Figure 3. NCEP grid points used to select NCEP predictors. 
the predicted and observed values. MLP neural network is composed of an input layer, any number of hidden layers, and an output layer of neurons. Single hidden layer is often considered enough to approximate continuous functions, but there is no widely accepted rule regarding the number of hidden nodes (Harpham and Dawson 2006; Hsieh 2009; Gaitan et al. 2013).

Usually, statistical techniques assume some kinds of data distribution, while MLP makes no assumption. MLP can be trained to approximate virtually any smooth, measurable function. It can model highly non-linear functions and can be trained to accurately generalize when presented with new and unseen data. These features of MLP make it an attractive alternative to develop numerical models, and also when choosing between statistical approaches (Gardner and Dorling 1998). MLP used following equations for modelling precipitation:

$$
y_{k}=F\left(\sum_{j=1}^{h} w_{j} G\left(s_{i}\right)+b_{k}\right)
$$

where $F$ represents the linear activation function of the output neuron, $b_{k}$ is the threshold; $w_{j}$ represents the connection, $G$ is the hyperbolic tangent sigmoid used as activation function for the hidden nodes, and can be expressed as follows:

$$
G\left(s_{i}\right)=\frac{e^{s_{i}}-e^{-s_{i}}}{e^{s_{i}}+e^{-s_{i}}}
$$

where $s_{i}$ is the weighted sum of all incoming information and is also referred to as the input signal,

$$
s_{i}=\sum_{i=1}^{n} w_{i} x_{i}
$$

where $x_{i}$ is the inputs to the network, $w_{i}$ is the connection weights between nodes of the input and hidden layers.

\subsection{Selection of predictors}

The selection of appropriate predictors is one of the most important steps for climate downscaling. Predictors that directly affect rainfall processes should be used in statistical downscaling as input variables (Salvi et al. 2013). The choice of predictors varies from one station to another as it depends on the characteristics of the large-scale atmospheric circulation and the local predictand. In this study, principal components of all NCEP variables from all the 20 grids were used for selecting predictors. Principal component analysis (PCA) is a multivariate statistical technique that has been widely used in climatological studies. It aims to reduce the dimensionality of a dataset consisting of a large number of interrelated variables, while retaining as much as possible of the variation present in the dataset (Hannachi et al. 2007).

One of the main difficulties in using PCA is the selection of the number of principal components (PCs). The key issue in developing a PCA model is to choose the adequate number of PCs to represent the system in an optimal way. If fewer PCs are selected than required, a poor model will be obtained, and an incomplete representation of the process results. On the contrary, if more PCs than necessary are selected, the model will be overparameterized and will include noise (Valle et al. 1999). There exist a plethora of methods to calculate the number of PCs (Akaike 1974; Malinowski 1977; Rissanen 1978). In the present study, Minimum Description Length (MDL) method was used for the selection of PCs. The MDL method applies to PCA based on the covariance matrix of the data. The advantage of the MDL criteria is that it has a solid statistical basis and is theoretically shown to have a minimum number of PCs (Valle et al. 1999).

\subsection{Performance evaluation of downscaling model}

The performance of the downscaling model was assessed by comparing the mean, variance, and quartiles (25th, 50th, and 75th) of observed and downscaled rainfall during both the model calibration and validation. Furthermore, different statistics like RMSE, coefficient of determination $\left(R^{2}\right)$, mean bias (MBE) and Nash-Sutcliffe model efficiency (NSE) were also estimated to show the efficiency of downscaling model. These statistical parameters were chosen as those are widely used for assessing downscaling model efficiency (Kannan and Ghosh 2013; Pervez and Henebry 2014). The equation used for calculating these parameters are given below:

$$
\begin{gathered}
\mathrm{RMSE}=\left[\frac{1}{N} \sum_{i=1}^{N}\left(x_{\mathrm{sim}, i}-x_{\mathrm{obs}, i}\right)^{2}\right]^{1 / 2} \\
R=\frac{\sum_{i=1}^{N}\left(x_{\mathrm{obs}, i}-\overline{x_{\mathrm{obs}}}\right)\left(x_{\mathrm{sim}, i}-\overline{x_{\mathrm{sim}}}\right)}{\sqrt{\sum_{i=1}^{N}\left(x_{\mathrm{sim}, i}-\overline{x_{\mathrm{sim}}}\right)^{2} \sum_{i=1}^{N}\left(x_{\mathrm{obs}, i}-\overline{x_{\mathrm{obs}}}\right)^{2}}} \\
\mathrm{MBE}=\left[\frac{1}{N} \sum_{i=1}^{N}\left(x_{\mathrm{sim}, i}-x_{\mathrm{obs}, i}\right)\right] \\
\mathrm{NSE}=1-\frac{\sum_{i=1}^{N}\left(x_{\mathrm{sim}, i}-x_{\mathrm{obs}, i}\right)^{2}}{\sum_{i=1}^{N}\left(x_{\mathrm{obs}, i}-\overline{x_{\mathrm{obs}}}\right)^{2}}
\end{gathered}
$$


where $x_{\text {sim }}$ and $x_{\text {obs }}$ are the $i$ th modeled and observed data, and $N$ is the number of observations.

\section{Results and discussion}

\subsection{Calibration and validation of model}

The MLP model was calibrated with NCEP predictors for the time period 1961-1990 and validated for the time period 1991-2001 against the observed precipitation. The period 1961-1990 was used as a base-line because it is of sufficient duration to establish a reliable climatology, yet not too long, nor too contemporary to include a strong global change signal (Wilby et al. 2004). All the stations were calibrated and validated separately.

\subsection{Selection of predictors}

The climatic system is influenced by the combined action of multiple atmospheric variables in a wide tempo-spatial space. Any single circulation predictor and/or small tempo-spatial space are unlikely to be sufficient, as they fail to capture key rainfall mechanisms based on thermodynamics and vapour content (Wilby 1998). Therefore, the NCEP data from 20 grid points (26 climate variables in each grid point; i.e., $26 \times 20=520$ attributes in total) was extracted to capture key rainfall mechanism. The model was trained with NCEP variables for 30 years (1961-1990), and, therefore, the sample size was $30 \times 12=360$. The multi-dimensional gridded NCEP predictors are highly correlated among each other and formed high-dimensional covariate, which results in multicollinearity. PCA was performed to reduce the dimensionality of the predictor variables. The number of components selected and the cumulative percentage of variance represented by the selected components for different months are given in table 3 . The first 24 principal components were found to represent more than $98 \%$ variability of the original dataset for most of the months.

\subsection{Calibration and validation results of downscaling model}

After the selection of predictors, MLP neural network is applied at every station to downscale rainfall. Initially, the performance of the calibrated and validated model was not very promising. The comparison of monthly mean observed and monthly mean downscaled rainfall had large differences. It was also found that the seasonal distribution of the downscaled rainfall is not following the pattern of observed rainfall. These types of variations are common in the arid region as the
Table 3. Number of principal components and the cumulative variance represented by the selected principle components in each month.

\begin{tabular}{lcc}
\hline Month & $\begin{array}{c}\text { No. of } \\
\text { components }\end{array}$ & $\begin{array}{c}\text { Cumulative } \\
\text { variance (\%) }\end{array}$ \\
\hline January & 24 & 98.94 \\
February & 25 & 99.17 \\
March & 25 & 98.95 \\
April & 25 & 98.86 \\
May & 25 & 98.87 \\
June & 26 & 98.86 \\
July & 24 & 98.91 \\
August & 24 & 98.70 \\
September & 24 & 98.71 \\
October & 24 & 98.88 \\
November & 25 & 99.03 \\
December & 23 & 98.90 \\
\hline
\end{tabular}

rainfall in such region is a heterogeneous climate variable and is difficult to simulate accurately (Wilby et al. 2002). Therefore, the rainfall occurrence in the study area was analyzed for better understanding and more precise simulation.

The analysis of seasonal rainfall pattern revealed that monsoon and western depressions are not effective for all stations in the study area. There is a wide variation in the amount of rainfall from these two sources. Some stations receive more rainfall during the monsoon, while some receive more rainfall during western depressions. Only the stations at Barkhan, Sibbi, Lasbela and Khuzdar receive $50 \%$ of its total rainfall during the monsoon. It was also observed that there are large variations in rainfall from month to month. These variations in rainfall have a great effect on the results of downscaling.

In order to deal with such problems, rainfall in each calendar month were downscaled separately, and later combined to produce the rainfall time series. For this purpose, macros in MS Excel were developed, which were used to separate rainfall data of each month from the rainfall time series. The separated data were used to calibrate and validate MLP model. Comparisons of the results showed that this procedure is much effective for downscaling rainfall in the arid region. It was observed that the downscaled mean rainfall and seasonal distribution in rainfall obtained by such a procedure are very close to the observed values.

The performance of the downscaling model was numerically assessed by comparing the mean and variance of observed and modelled rainfall during both model calibration and validation. The obtained results are presented in table 4 . It can be seen from the table that downscaling model 
has reproduced the observed precipitation with a good accuracy during model calibration. However, rainfall was found to be little over- or underpredicted in some stations during model validation. For example, at Khuzdar, the observed precipitation was $25.55 \mathrm{~mm}$, while model produces 21.93 $\mathrm{mm}$. Similarly, at Zhob station, observed precipitation was $24.79 \mathrm{~mm}$, but the model produced $20.31 \mathrm{~mm}$. However, the model was found to downscale mean precipitation more accurately during validation at Jiwani and Turbat stations. Similar types of results were obtained by Pervez and Henebry (2014) during downscaling precipitation in Ganges-Brahmaputra basin, where the downscaling model was found to perform better during model validation in most of the stations.
In general, the variance in observed precipitation is much greater than the variance in atmospheric variables obtained from reanalysis or GCM. Therefore, downscaling models fail to capture the full range of variance in precipitation (Wilby et al. 2004). The result of this study also supports that the performance of downscaling model in capturing variance was not as good as in capturing mean precipitation. However, the model was still compatible to capture variance to some extent in most of the stations. For example, at Barkhan station, the variance of observed and downscaled precipitation was 1.22 and 1.03 , respectively. Large differences were also observed in few stations during model calibration and validation. For example, variance in precipitation during model validation was 3.25

Table 4. The mean and coefficient of variation for observed and modeled precipitation during model calibration and validation.

\begin{tabular}{|c|c|c|c|c|c|c|c|c|}
\hline \multirow[b]{3}{*}{ Station } & \multicolumn{4}{|c|}{ Calibration period (1961-1990) } & \multicolumn{4}{|c|}{ Validation period (1991-2001) } \\
\hline & \multicolumn{2}{|c|}{ Mean } & \multicolumn{2}{|c|}{ Coefficient of variation } & \multicolumn{2}{|c|}{ Mean } & \multicolumn{2}{|c|}{ Coefficient of variation } \\
\hline & Obs & Mod & $\overline{\mathrm{Obs}}$ & Mod & Obs & Mod & $\overline{\mathrm{Obs}}$ & Mod \\
\hline Barkhan & 30.48 & 30.56 & 1.39 & 1.14 & 36.44 & 34.62 & 1.22 & 1.03 \\
\hline Dalbandin & 6.71 & 6.89 & 1.96 & 1.48 & 7.30 & 6.98 & 1.97 & 1.32 \\
\hline Jiwani & 9.49 & 8.12 & 2.93 & 1.71 & 7.63 & 8.01 & 2.49 & 1.61 \\
\hline Kalat & 11.21 & 11.17 & 2.02 & 1.59 & 18.66 & 17.54 & 1.50 & 1.23 \\
\hline Khuzdar & 19.39 & 20.27 & 1.52 & 1.22 & 25.11 & 21.93 & 1.75 & 1.15 \\
\hline Lasbela & 11.56 & 11.41 & 2.05 & 1.61 & 14.93 & 15.55 & 2.11 & 1.37 \\
\hline Nokkundi & 2.95 & 2.79 & 3.14 & 2.00 & 2.19 & 2.62 & 3.25 & 1.71 \\
\hline Panjgur & 8.12 & 8.14 & 2.93 & 1.87 & 9.07 & 9.19 & 2.40 & 1.64 \\
\hline Pasni & 9.11 & 9.04 & 2.61 & 1.68 & 7.93 & 8.83 & 1.75 & 1.18 \\
\hline Quetta & 21.73 & 21.56 & 1.66 & 1.31 & 20.50 & 21.01 & 1.66 & 1.22 \\
\hline Sibbi & 11.78 & 12.29 & 2.11 & 1.37 & 16.29 & 13.41 & 1.45 & 1.26 \\
\hline Turbat & 8.36 & 7.49 & 2.03 & 1.30 & 6.23 & 6.98 & 2.33 & 1.41 \\
\hline Zhob & 23.75 & 23.23 & 1.30 & 1.09 & 24.80 & 20.31 & 1.16 & 0.87 \\
\hline
\end{tabular}
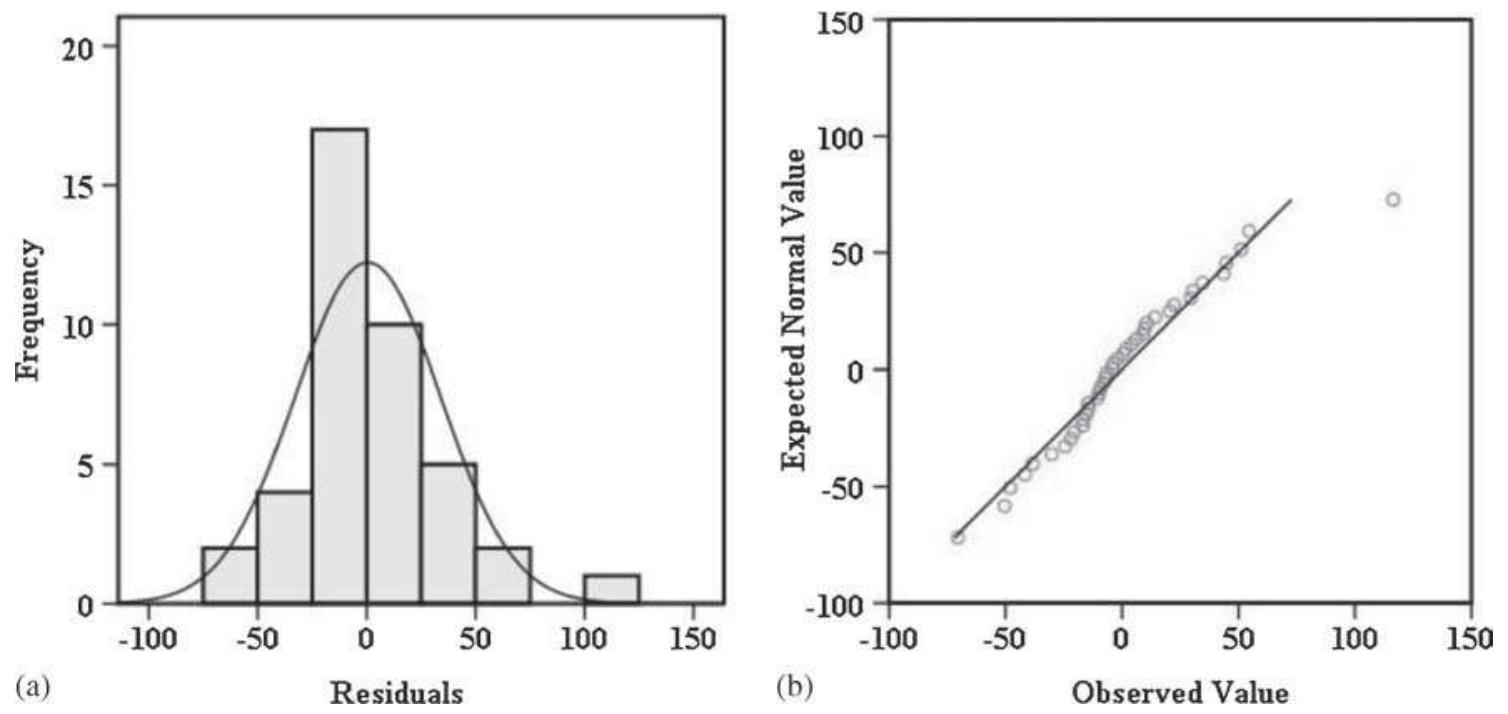

Figure 4. (a) Frequency distribution and (b) normal Q-Q plot of residuals. 
at Nokkunddi station. But it was found 1.71 in downscaled precipitation.

Sachindra et al. (2014) reported that downscaling model run with reanalysis data tends to explain the mid-range of variances more accurately compared to extremes. The result of the present study also supports the statement. Variance inflation methods can be used to capture full range of variance (Sohn et al. 2013; Hu et al. 2013; Pervez and Henebry 2014). Von Storch (1999) suggested that the application of randomization techniques can help in capturing the full variance of a predictand. Tripathi et al. (2006) reported that variations in downscaled data can be improved by considering a wider range of predictor variables and a much longer validation phase.

The residuals of downscaled model for each month at each station was assessed for normality. This was done by visual assessment of histograms and $\mathrm{Q}-\mathrm{Q}$ plots of the residuals. The histogram and Q-Q plot of the residuals at Quetta station for the month of February are shown in figure 4(a and b), respectively. The histogram closely resembles a normal distribution and the $\mathrm{Q}-\mathrm{Q}$ plot supports the normal distribution of the residuals.

Similar results were observed for most of the months at all the stations. However, in some months deviation from normality was also found at few stations. This may be due to the presence of outliers in the series. Slight deviation from normality of residuals is not a serious issue if the interest is only in the mean of the conditional distribution. However, when interest is in the tails of the conditional distribution, the distribution of residuals becomes important (Tareghian and Rasmussen 2013).

\subsubsection{Time series analysis}

The monthly time series of observed and downscaled rainfall was compared to show the efficacy of the downscaling method during model calibration and validation. The comparison was carried out at all stations individually. The results for three stations located in different climate zones, i.e., hyper-arid, arid, and semi-arid regions are presented as example in figure 5.

It can be seen that monthly rainfall follows the similar pattern like the observed rainfall. At few stations, some months have very high rainfall values, which were underpredicted by the model. The occurrence of extreme events is a common phenomenon in precipitation hydrology, which often cannot be predicted by NCEP predictors. Tripathi et al. (2006) reported that the downscaling model fails to capture the extreme precipitation. However, it can successfully capture the mean. It was observed that the model used in the study captured the mean and low precipitation accurately.

\subsubsection{Mean seasonal rainfall}

The study area receives most of the annual rainfall in two major seasons namely, monsoon and winter. Therefore, the observed and downscaled rainfall at 13 stations scattered over the study area were used to prepare the contour maps of monsoon and winter rainfall to compare the spatial distribution of seasonal rainfall constructed by the observed and downscaling model.

The contour maps are shown in figure 6. The rainfall during monsoon is divided into four contour lines from $<80-80,81-120,121-160$, and $>160 \mathrm{~mm}$, while winter season divided into $<70-70$, $71-80,81-90$, and $>90 \mathrm{~mm}$. The contours were prepared by interpolating observed and downscaled rainfall in ArcGIS by using the Kriging technique. It can be seen from the figures that the downscaled rainfall produced similar pattern of contours like the observed rainfall.

\subsubsection{Quartiles}

The 25th, 50th and 75th quantiles of observed and simulated precipitation were also assessed to evaluate the performance of the downscaling model. The 25th quartile considers the lowest $25 \%$, the 50 th quartile considers the $50 \%$, and the 75 th quartile considers the highest $25 \%$ data. The purpose of this test was to assess whether the observed and the simulated data have the same quartiles. The assessment was done separately in each station, and the obtained results are presented in table 5 .

It can be seen from table 5 that model has overpredicted the 25th quartile rainfall during both model calibration and validation. For example, at Barkhan station, the observed 25th quartile was 1.4 and the model quartile was 5.4 during model calibration. Similarly, the observed 25th quartile was 4.4 , but the model quartile was 8.0 during validation. However, the model was found satisfactory in replicating 50th and 75 th percentiles during both model calibration and validation. For example, at Barkhan station, the observed and the modeled 50th quartiles were 14.7 and 15.5, respectively during model calibration, and 20.4 and 21.3, respectively during model validation.

Box plots of observed and downscaled rainfall during model calibration and validation are also prepared to show the efficiency of MLP downscaling model in replicating rainfall range. The box plots for three selected stations located in semiarid, arid, and hyper-arid regions are shown in 

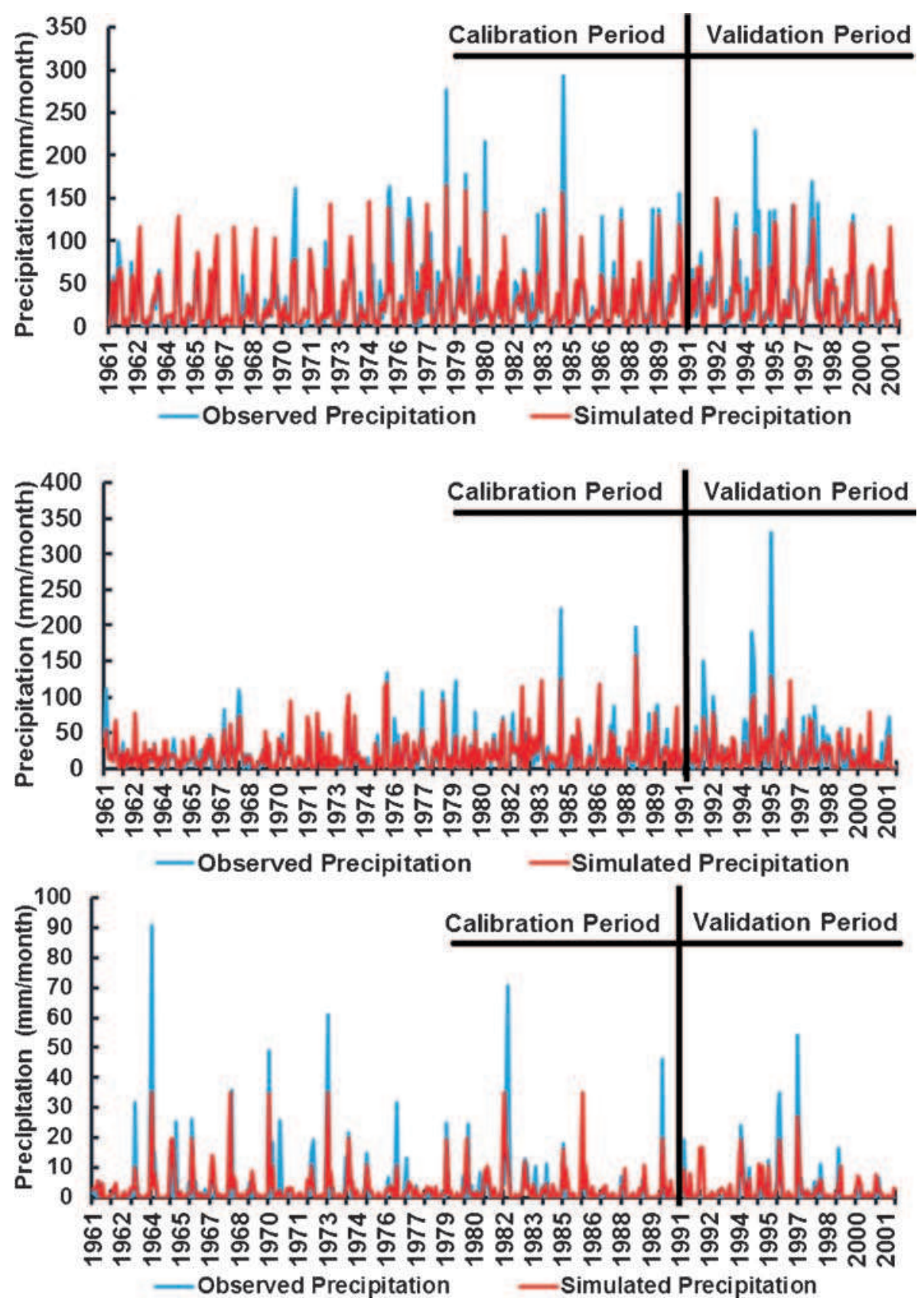

Figure 5. Observed and downscaled rainfall time series at (a) Barkhan (semi-arid), (b) Khuzdar (arid), and (c) Nokkundi (hyper-arid) stations.

figure 7 as example. The lower and upper lines of the boxes give the 25 th and 75 th quartiles rainfall values, whereas a middle line of the box gives the median rainfall. It can be seen from the figure that the model was successfully able to capture median and quartiles in most of the cases. It should be noted that outliers are very common in rainfall data in the study area and, therefore, rainfall distribution is positively skewed in most of the stations. However, normal distribution and left-skewed is also found in a few stations. The box plots show that the downscaled model is successfully able to capture the skewness in the data.

\subsubsection{Root mean squared error (RMSE)}

The RMSE explains the difference between observed and downscaled precipitation, and, therefore, it provides the spread of error or the performance of the model. The RMSE in model rainfall at different stations is shown in table 6 . It can be seen from the table that different stations have different RMSE during model calibration and validation, but in most of the stations the estimated errors during model calibration and validation were very near. The Barkhan station, which receives the highest rainfall, produced highest RMSE of 24.43, 


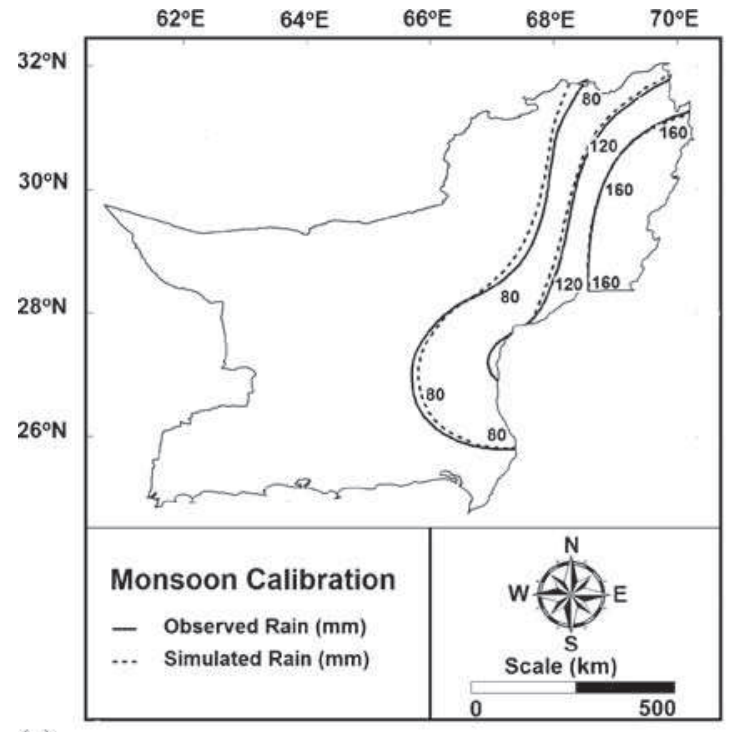

(a)

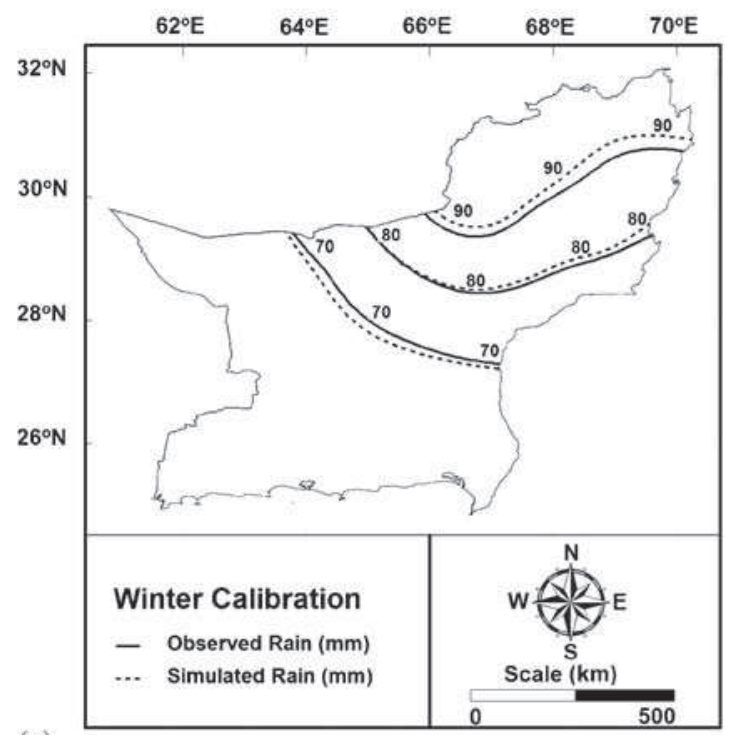

(c)

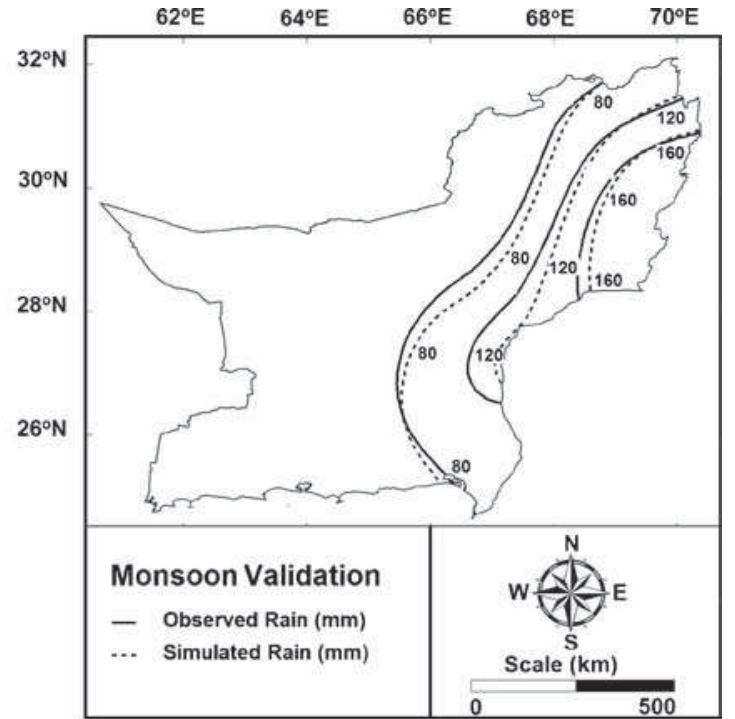

(b)

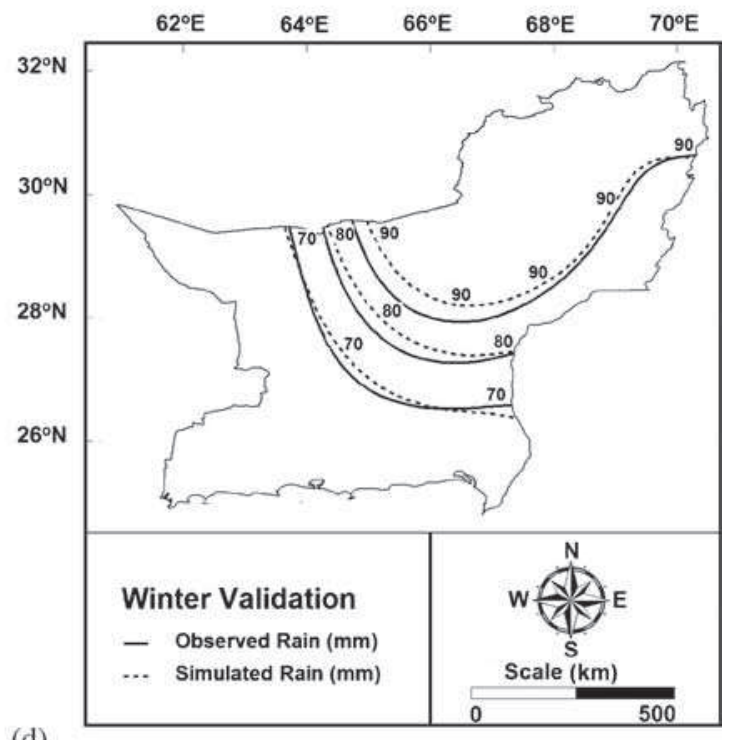

(d)

Figure 6. Contour maps of mean monsoon rainfall during model (a) calibration, (b) validation; winter rainfall during model, (c) calibration and (d) validation.

while Nokkunddi, which receives the lowest rainfall, produced lowest error of 7.13 during model calibration. Khuzdar and Zhob stations which fall in the arid region produce highest RMSE during model validation.

\subsubsection{Coefficient of determination}

The scatter plots of observed and downscaled precipitation for different stations located in different climatic zones during model calibration and validation are shown in figure 8. It can be seen from the figure that the model has underpredicted extreme rainfall values in almost all the stations. However, the model was found to reproduce low precipitation efficiently. The coefficient of determination values were found above 0.5 in almost all stations during model calibration. However, the performance of the model during validation was less accurate compared to model calibration. The coefficient of determination values were found above 0.4 in most of the stations during model validation.

\subsubsection{Mean bias error}

Mean bias error (MBE) measures the average difference between two datasets and, therefore, provides a useful measure of the degree of under- or over-estimates by the model. The MBE in modelled rainfall at different stations during calibration 
Table 5. Comparison of quartiles between observed and modelled data during both model calibration and validation.

\begin{tabular}{|c|c|c|c|c|c|c|c|c|c|c|c|c|}
\hline \multirow[b]{3}{*}{ Station } & \multicolumn{6}{|c|}{ Calibration period (1961-1990) } & \multicolumn{6}{|c|}{ Validation period (1991-2001) } \\
\hline & \multicolumn{2}{|c|}{25 th } & \multicolumn{2}{|c|}{50 th } & \multicolumn{2}{|c|}{75 th } & \multicolumn{2}{|c|}{25 th } & \multicolumn{2}{|c|}{50 th } & \multicolumn{2}{|c|}{75 th } \\
\hline & $\overline{\mathrm{Obs}}$ & Mod & $\overline{O b s}$ & Mod & $\overline{\mathrm{Obs}}$ & Mod & $\overline{\mathrm{Obs}}$ & Mod & $\overline{O b s}$ & Mod & $\overline{\mathrm{Obs}}$ & Mod \\
\hline Barkhan & 1.4 & 5.4 & 14.7 & 15.5 & 45 & 49.3 & 4.4 & 8.0 & 20.4 & 21.3 & 49.1 & 53.7 \\
\hline Dalbandin & 0.0 & 0.2 & 0.3 & 1.9 & 6.5 & 8.7 & 0.0 & 0.2 & 0.0 & 2.7 & 7.0 & 10.1 \\
\hline Jiwani & 0.0 & 0.0 & 0.0 & 0.9 & 5.3 & 10.1 & 0.0 & 0.0 & 0.0 & 1.7 & 2.1 & 9.1 \\
\hline Kalat & 0.0 & 0.4 & 0.0 & 2.9 & 11.4 & 13.6 & 0.0 & 1.2 & 5.6 & 8.7 & 25.2 & 26.6 \\
\hline Khuzdar & 0.5 & 1.2 & 8.3 & 12.9 & 25.1 & 28.5 & 0.1 & 2.3 & 9.2 & 14 & 32 & 33.2 \\
\hline Lasbela & 0.0 & 0.3 & 0.0 & 3.3 & 12.7 & 14.2 & 0.0 & 0.9 & 0.8 & 7.6 & 15.3 & 21.7 \\
\hline Nokkundi & 0.0 & 0.0 & 0.0 & 1.0 & 1.2 & 3.2 & 0.0 & 0.1 & 0.0 & 0.8 & 0.1 & 3.2 \\
\hline Panjgur & 0.0 & 0.0 & 0.0 & 0.3 & 3.0 & 10 & 0.0 & 0.0 & 0.0 & 1.6 & 6.3 & 12.2 \\
\hline Pasni & 0.0 & 0.6 & 0.0 & 4.7 & 10 & 11.7 & 0.0 & 0.9 & 0.0 & 5.2 & 12.4 & 12.7 \\
\hline Quetta & 0.0 & 0.1 & 2.8 & 8.5 & 30 & 33.1 & 0.0 & 1.0 & 4.3 & 8.5 & 30.1 & 31.8 \\
\hline Sibbi & 0.0 & 0.2 & 0.0 & 5.0 & 11 & 17.0 & 0.0 & 1.9 & 5.8 & 6.6 & 22.4 & 20.1 \\
\hline Turbat & 0.0 & 1.0 & 2.3 & 3.7 & 8.8 & 10.6 & 0.0 & 0.7 & 0.0 & 2.4 & 5.0 & 10.3 \\
\hline Zhob & 1.3 & 5.5 & 12.9 & 14.4 & 30.2 & 31.3 & 3.2 & 6.2 & 15.1 & 17.9 & 36.3 & 30.7 \\
\hline
\end{tabular}

Table 6. Correlation coefficient, RMSE, MBE, and NSE during model calibration and validation.

\begin{tabular}{|c|c|c|c|c|c|c|c|c|}
\hline \multirow[b]{2}{*}{ Station } & \multicolumn{4}{|c|}{ Calibration period (1961-1990) } & \multicolumn{4}{|c|}{ Validation period (1991-2001) } \\
\hline & $R^{2}$ & RMSE & $\begin{array}{c}\text { Mean } \\
\text { bias }\end{array}$ & NSE & $R^{2}$ & RMSE & $\begin{array}{c}\text { Mean } \\
\text { bias }\end{array}$ & NSE \\
\hline Barkhan & 0.67 & 24.43 & 0.08 & 0.67 & 0.63 & 26.90 & -1.82 & 0.63 \\
\hline Dalbandin & 0.58 & 8.56 & 0.18 & 0.58 & 0.55 & 9.72 & -0.32 & 0.54 \\
\hline Jiwani & 0.38 & 22.13 & -1.37 & 0.36 & 0.45 & 14.09 & 0.38 & 0.45 \\
\hline Kalat & 0.71 & 12.18 & -0.04 & 0.71 & 0.54 & 18.98 & -1.12 & 0.54 \\
\hline Khuzdar & 0.72 & 15.44 & 0.88 & 0.72 & 0.51 & 31.35 & -3.18 & 0.49 \\
\hline Lasbela & 0.64 & 14.30 & -0.15 & 0.64 & 0.46 & 23.01 & 0.61 & 0.46 \\
\hline Nokkunddi & 0.40 & 7.13 & -0.16 & 0.40 & 0.49 & 5.09 & 0.44 & 0.48 \\
\hline Panjgur & 0.48 & 17.24 & 0.02 & 0.47 & 0.56 & 14.45 & 0.12 & 0.55 \\
\hline Pasni & 0.61 & 10.79 & -0.06 & 0.60 & 0.45 & 10.35 & 0.91 & 0.44 \\
\hline Quetta & 0.61 & 22.41 & -0.17 & 0.61 & 0.62 & 21.09 & 0.51 & 0.62 \\
\hline Sibbi & 0.43 & 18.73 & 0.51 & 0.43 & 0.61 & 15.08 & -2.88 & 0.59 \\
\hline Turbat & 0.39 & 13.36 & -0.87 & 0.38 & 0.50 & 10.27 & 0.75 & 0.49 \\
\hline Zhob & 0.74 & 15.74 & -0.52 & 0.74 & 0.06 & 29.90 & -4.49 & -0.09 \\
\hline
\end{tabular}

and validation are presented in table 6 . It can be seen from the table that MBEs vary widely in the study area. The precipitation was found slightly overestimated in most of the stations during model calibration. However, at Barkhan, Kalat, Panjgur and Pasni stations, MBE were found very close to zero. The rainfall was found to be underpredicted only at Barkhan, Dalbandin, Kalat, Khuzdar, Sibbi and Zhob during model validation. Highest negative bias was observed at Zhob station. On the other hand, positive bias was observed at Pasni station. It was observed that there was no consistency in the biases during model calibration and validation. The sign of biases varies from positive to negative during model calibration and validation at most of the stations. For example, at Barkhan station, positive bias was observed during calibration, while negative bias was observed during validation.

\subsubsection{Nash-Sutcliffe model efficiency}

The model performance was further assessed by Nash-Sutcliff efficiency (NSE). The obtained results are presented in table 6 . The NSE values were found above 0.5 in most of the stations. Highest NSE was observed at Zhob station while the 

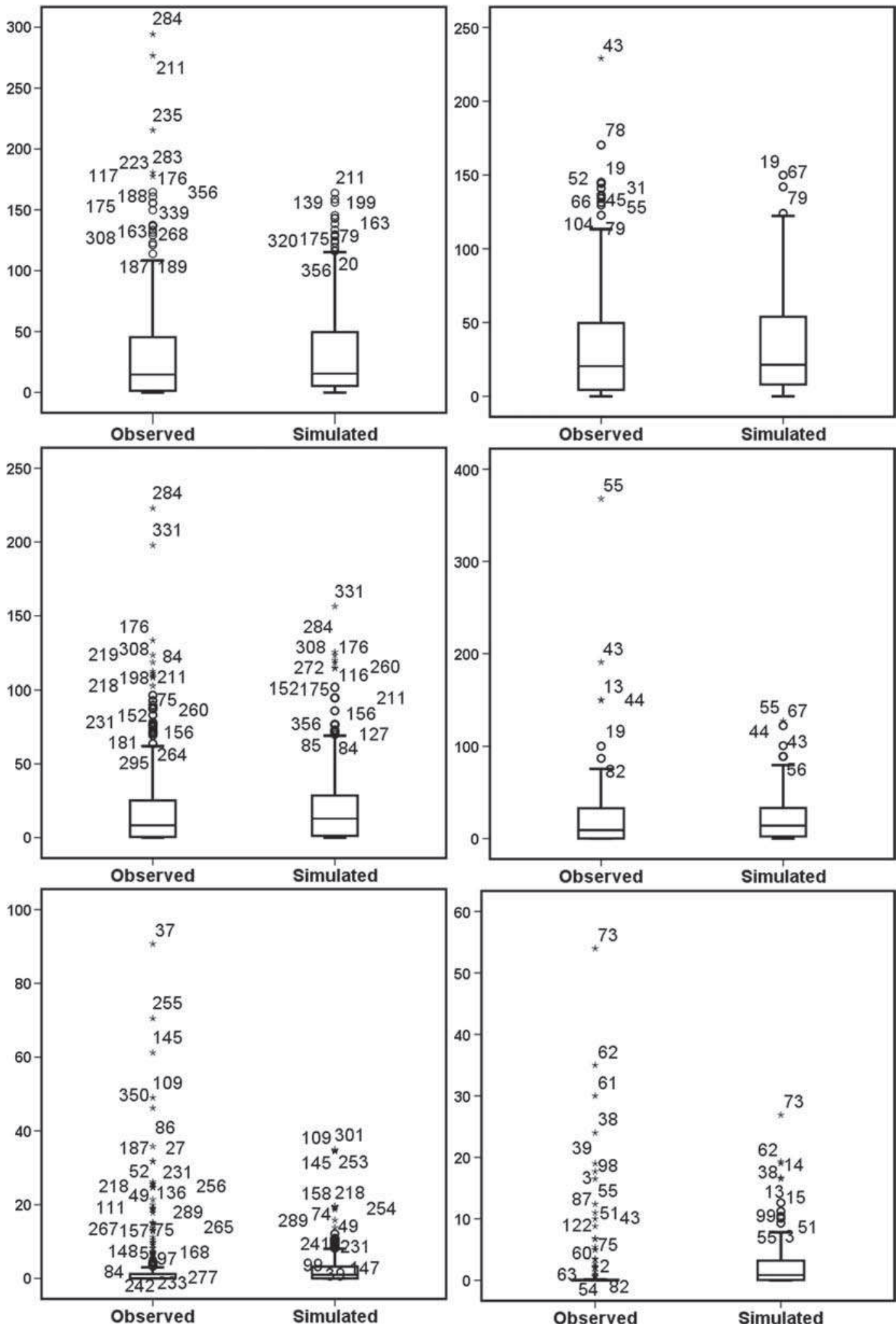

Figure 7. Box plots of rainfall data during model calibration at (a) Barkhan (semi-arid), (c) Khuzdar (arid), (e) Nokkundi (hyper-arid), and during model validation at (b) Barkhan (semi-arid), (d) Khuzdar (arid) and (f) Nokkundi (hyper-arid) stations.

lowest was observed at Jiwani station during model calibration. On the other hand, the highest NSE was obtained at Barkhan station, and the lowest was observed at Zhob station during model validation. At Zhob station, NSE was found highest during calibration, but lowest during validation. This is 

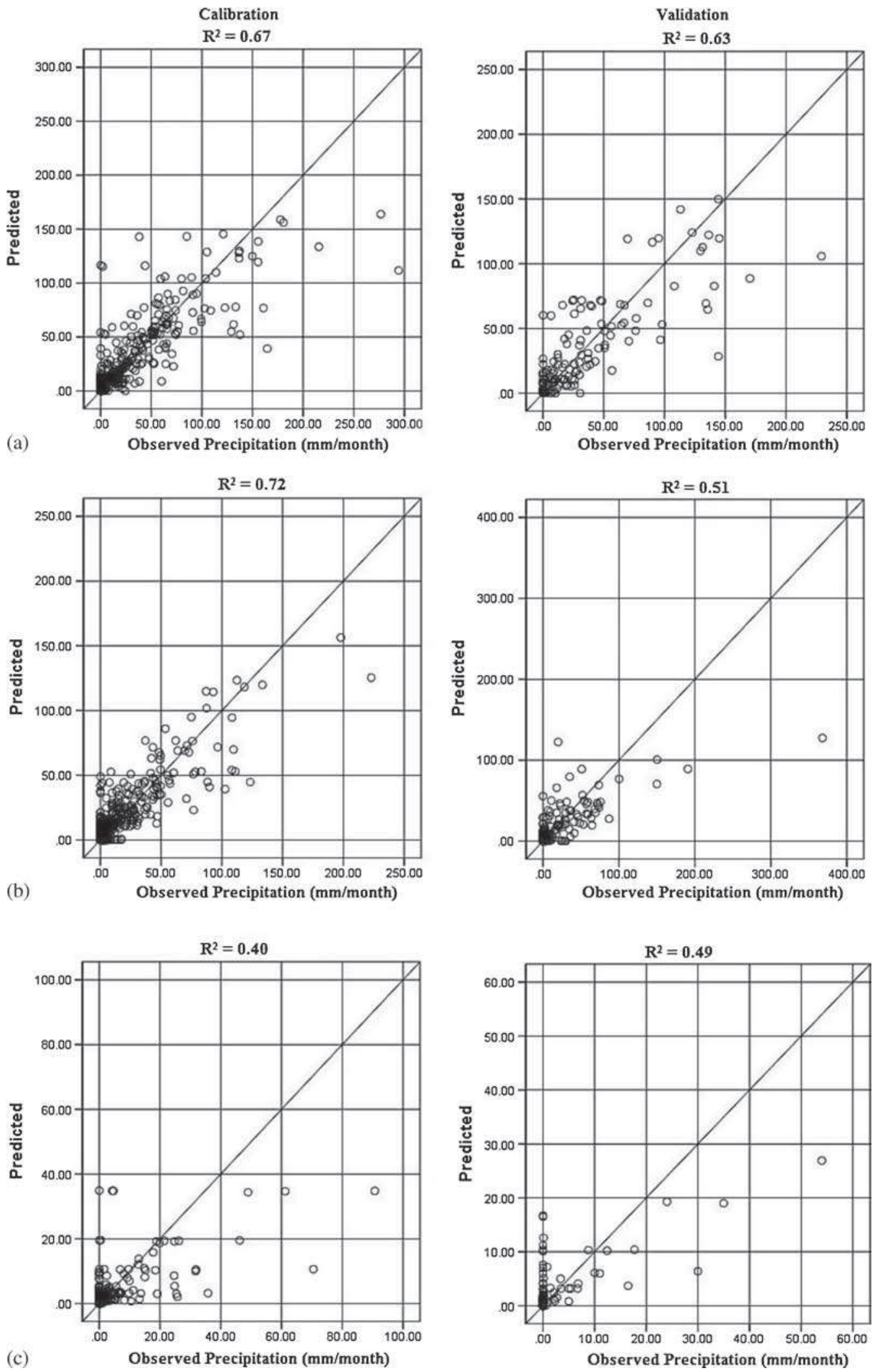

Figure 8. Scatter plot of observed and downscaled rainfall at (a) Barkhan (semi-arid), (b) Khuzdar (arid), and (c) Nokkundi (hyper-arid) stations during model calibration and validation.

due to the large variation in precipitation between model calibration and validation periods at this station. Overall, the performance of the model at
Barkhan, Dalbandin, Kalat and Quetta was found satisfactory with NSE value more than 0.5 during both model calibration and validation. 


\section{Conclusions}

The performance of the multilayer perceptron neural network in downscaling monthly rainfall in the arid region has been evaluated in the present study. The MLP model was calibrated using observed monthly rainfall at 13 stations located in the arid Baluchistan province of Pakistan. The model performance was evaluated by assessing its ability in reproducing different statistical parameters namely, mean, standard deviation, quartiles, RMSE, $R^{2}$, MBE, and NSE. The results revealed that the multilayer perceptron neural network model was capable to downscale precipitation in most of the stations in the study area satisfactorily. Statistical downscaling of rainfall in the arid region is often very difficult due to erratic rainfall pattern, and poor understanding of the relation between local rainfall and ocean-atmospheric circulation parameters. The results obtained in this study indicate that an MLP neural network can be used downscaling monthly rainfall in such regions.

The following points should be noted for future studies on climate downscaling in arid region:

(1) The NCEP reanalysis datasets only from 20 grid points around the study area were used in the present study for the selection of predictors for downscaling rainfall in the present study. The spatial domain covered by 20 grid points may not be enough to capture the regional synoptic circulation patterns that contribute to the anomalous rainfall pattern in arid region. The NCEP reanalysis dataset from more grid points can be used in future for the selection of predictors for more accurate replication of observed rainfall.

(2) The MLP downscaling model was trained using first $70 \%$ and tested with the rest $30 \%$ of the data. This approach of model calibration and validation is often not enough to capture large variations in precipitation in arid region. Random selection of training and testing of data can be used to improve the efficiency of downscaling model.

(3) Multilayer perceptron neural network and principal component analysis were used in the present study for downscaling of rainfall and selection of predictors, respectively. Other data mining and predictor selection approaches can be used to assess the performance of different methods in downscaling rainfall in arid regions. Another scope of present work is to project the precipitation and the results can be analyzed for climate change and variability.

\section{Acknowledgements}

The authors are grateful to Ministry of Higher Education (MOHE)-Malaysia and Universiti Teknologi Malaysia (UTM) for providing financial support for this research through FRGS research project (Vote No. R.J130000.7822.4F541). Authors are also grateful to the anonymous reviewers for their valuable comments and suggestions to improve the quality of the paper.

\section{References}

Ahmadi A, Moridi A, Lafdani E and Kianpisheh G 2014 Assessment of climate change impacts on rainfall using large scale climate variables and downscaling models - A case study; J. Earth Syst. Sci. 123(7) 1603-1618.

Ahmed K, Shahid S and Harun S B 2014 Spatial interpolation of climatic variables in a predominantly arid region with complex topography; Environment Systems and Decisions 34 555-563.

Akaike H 1974 Information theory and an extension of the maximum likelihood principle; In: Proceedings 2nd International Symposium on Information Theory (eds) Petrov and Caski, pp. 267-281.

Akhtar M, Ahmad N and Booij M 2008 The impact of climate change on the water resources of HindukushKarakorum-Himalaya region under different glacier coverage scenarios; J. Hydrol. 355(1) 148-163.

Alamgir M, Shahid S, Hazarika M K, Nashrrullah S, Harin S B and Shamsudin S 2015 Analysis of meteorological drought pattern during different climatic and cropping seasons in Bangladesh; J. Am. Water Resourc. Assoc., doi: $10.1111 /$ jawr.12276.

Alexandersson H 1986 A homogeneity test applied to precipitation data; J. Climatol. 6(6) 661-675.

Anandhi A, Srinivas V V, Nanjundiah R S and Nagesh Kumar D 2008 Downscaling precipitation to river basin in India for IPCC SRES scenarios using support vector machine; Int. J. Climatol. 28(3) 401-420.

Ashiq M W, Zhao C, Ni J and Akhtar M 2010 GIS-based high-resolution spatial interpolation of precipitation in mountain-plain areas of Upper Pakistan for regional climate change impact studies; Theoret. Appl. Climatol. 99(3-4) 239-253.

Cannon A J 2008 Probabilistic multisite precipitation downscaling by an expanded Bernoulli-Gamma density network; J. Hydrometeor. 9(6) 1284-1300.

Chadwick R, Coppola E and Giorgi F 2011 An artificial neural network technique for downscaling GCM outputs to RCM spatial scale; Nonlin. Process. Geophys. 18 1013-1028.

Chen Y N and Xu Z X 2005 Plausible impact of global climate change on water resources in the Tarim River Basin; Sci. China Ser D, Earth Sci. 48(1) 65-73.

Chiew F H S 2006 Estimation of rainfall elasticity of streamflow in Australia; Hydrol. Sci. J. 51(4) 613-625.

Chu J T, Xia J, Xu C Y and Singh V P 2010 Statistical downscaling of daily mean temperature, pan evaporation and precipitation for climate change scenarios in Haihe River, China; Theoret. Appl. Climatol. 99(1-2) 149-161.

Dawson C W and Wilby R L 2001 Hydrological modelling using artificial neural networks; Progr. Phys. Geogr. 25(1) 80-108. 
Firat M, Dikbas F, Koç A C and Gungor M 2010 Missing data analysis and homogeneity test for Turkish precipitation series; Sadhana 35(6) 707-720.

Gaitan C, Hsieh W and Cannon A 2014 Comparison of statistically downscaled precipitation in terms of future climate indices and daily variability for southern Ontario and Quebec, Canada; Clim. Dyn. 43(12) 3201-3217.

Gaitan C, Hsieh W, Cannon A and Gachon P 2013 Evaluation of linear and non-linear downscaling methods in terms of daily variability and climate indices: Surface temperature in southern Ontario and Quebec, Canada; Atmos.-Ocean. 52(3) 211-221.

Gardner M W and Dorling S R 1998 Artificial neural networks (the multilayer perceptron) - A review of applications in the atmospheric sciences; Atmos. Environ. 32(14-15) 2627-2636.

Goyal M K and Ojha C S P 2012 Downscaling of surface temperature for lake catchment in an arid region in India using linear multiple regression and neural networks; Int. J. Climatol. 32(4) 552-566.

Goyal M, Ojha C and Burn D 2011 Nonparametric statistical downscaling of temperature, precipitation, and evaporation in a semiarid region in India; J. Hydrol. Eng. 17(5) 615-627.

Goyal M, Burn D and Ojha C S P 2012 Evaluation of machine learning tools as a statistical downscaling tool: Temperatures projections for multi-stations for Thames River Basin, Canada; Theoret. Appl. Climatol. 108(3-4) 519-534.

Groisman P Y, Karl T R, Easterling D R, Knight R W, Jameson P F, Hennessy K J, Suppiah R, Page C M, Wibig J, Fortuniak K, Razuvaev V N, Douglas A, Forland E and Zhai P M 1999 Changes in the probability of heavy precipitation: Important indicators of climatic change; Clim. Change 42 243-283.

Guo J, Chen H, Xu C-Y, Guo S and Guo J 2012 Prediction of variability of precipitation in the Yangtze River Basin under the climate change conditions based on automated statistical downscaling; Stochastic Environ. Res. Risk Assess. 26(2) 157-176.

Hannachi A, Jolliffe I T and Stephenson D B 2007 Empirical orthogonal functions and related techniques in atmospheric science: A review; Int. J. Climatol. 27(9) 1119-1152.

Harpham C and Dawson C W 2006 The effect of different basis functions on a radial basis function network for time series prediction: A comparative study; Neurocomputing 69(16-18) 2161-2170.

Hashmi M Z, Shamseldin A Y and Melville B W 2011 Statistical downscaling of watershed precipitation using Gene Expression Programming (GEP); Environmental Modelling \& Software 26(12) 1639-1646.

Haylock M R, Cawley G C, Harpham C, Wilby R L and Goodess C M 2006 Downscaling heavy precipitation over the United Kingdom: A comparison of dynamical and statistical methods and their future scenarios; Int. J. Climatol. 26(10) 1397-1415.

Hosseinzadeh Talaee P, Kouchakzadeh M and Shifteh B 2014 Homogeneity analysis of precipitation series in Iran; Theoret. Appl. Climatol. 118(1-2) 297-305.

Hsieh W W 2009 Machine learning methods in the environmental sciences: Neural networks and kernels; Cambridge University Press.

Hu Y, Maskey S and Uhlenbrook S 2013 Downscaling daily precipitation over the Yellow River source region in China: A comparison of three statistical downscaling methods; Theoret. Appl. Climatol. 112(3-4) 447-460.

Huth R, Kliegrova S and Metelka L 2008 Non-linearity in statistical downscaling: Does it bring an improvement for daily temperature in Europe? Int. J. Climatol. 28(3) $465-477$.

Kajornrit J, Wong K and Fung C 2012 Estimation of missing precipitation records using modular artificial neural networks; In: Neural Information Processing (eds) Huang T, Zeng Z, Li C and Leung C, Springer-Berlin Heidelberg, pp. $52-59$.

Kannan S and Ghosh S 2013 A nonparametric kernel regression model for downscaling multisite daily precipitation in the Mahanadi basin; Water Resourc. Res. 49(3) 1360-1385.

Kannan S and Ghosh S 2011 Prediction of daily rainfall state in a river basin using statistical downscaling from GCM output; Stoch. Environ. Res. Risk Assess. 25(4) 457-474.

Lins H, Shiklomanov I and Stakhiv E 1990 Hydrology and water resources; In: Climate Change, the IPCC Scientific Assessment (eds) McTegart W J G and Griffiths D C, IPCC WG Report, WMO/UNEP. Ch. 4, pp. 1-42.

Liu Z, Xu Z, Charles S P, Fu G and Liu L 2011 Evaluation of two statistical downscaling models for daily precipitation over an arid basin in China; Int. J. Climatol. 31(13) 2006-2020

Mahmood R and Babel M 2013 Evaluation of SDSM developed by annual and monthly sub-models for downscaling temperature and precipitation in the Jhelum basin, Pakistan and India; Theoret. Appl. Climatol. 113(1-2) $27-44$.

Malinowski E R 1977 Determination of the number of factors and the experimental error in a data matrix; Anal. Chem. 49(4) 612-617.

Maraun D, Wetterhall F, Ireson A M, Chandler R E, Kendon E J, Widmann M, Brienen S, Rust $\mathrm{H}$ W, Sauter T, Themeßl M, Venema V K C, Chun K P, Goodess C M, Jones R G, Onof C, Vrac M and Thiele-Eich I 2010 Precipitation downscaling under climate change: Recent developments to bridge the gap between dynamical models and the end user; Rev. Geophys. 48(3) RG3003.

Maurer E P and Hidalgo H G 2008 Utility of daily vs. monthly large-scale climate data: An intercomparison of two statistical downscaling methods; Hydrol. Earth Syst. Sci. 12 551-563.

McLachlan G J and Krishnan T 1997 The EM algorithm and extensions; Wiley, New York.

Mehrotra D and Mehrotra R 1995 Climate change and hydrology with emphasis on the Indian subcontinent; Hydrol. Sci. J./Journal Des Sciences Hydrologiques 40(2) 231-242.

Mendes D and Marengo J 2010 Temporal downscaling: A comparison between artificial neural network and autocorrelation techniques over the Amazon Basin in present and future climate change scenarios; Theoret. Appl. Climatol. 100(3-4) 413-421.

Middelkoop H, Daamen K and Gellens D 2001 Impact of climate change on hydrological regimes and water resources management in the Rhine basin; Climatic Change 49 105-128.

Najafi M R, Moradkhani H and Wherry S A 2010 Statistical downscaling of precipitation using machine learning with optimal predictor selection; J. Hydrol. Eng. 16(8) 650-664.

Ng S K and McLachlan G J 2004 Using the EM algorithm to train neural networks: Misconceptions and a new algorithm for multiclass classification; Neural Networks, IEEE Trans. 15(3) 738-749.

Pervez M S and Henebry G M 2014 Projections of the Ganges-Brahmaputra precipitation - Downscaled from GCM predictors; J. Hydrol. 517 120-134.

Pour S H, Harun S B and Shahid S 2014 Genetic programming for the downscaling of extreme rainfall events on the East Coast of Peninsular Malaysia; Atmosphere 5(3) 914-936. 
Rissanen J 1978 Modelling by shortest data description; Automatica 14 465-471.

Rodrigo F S 2002 Changes in climate variability and seasonal rainfall extremes: A case study from San Fernando (Spain), 1821-2000; Theor. Appl. Climatol. 72 193-207.

Sachindra D A, Huang F, Barton A and Perera B J C 2014 Statistical downscaling of general circulation model outputs to precipitation - part 1: Calibration and validation; Int. J. Climatol. 34(11) 3264-3281.

Salvi K, Kannan S and Ghosh S 2013 High-resolution multisite daily rainfall projections in India with statistical downscaling for climate change impacts assessment; $J$. Geophys. Res.: Atmos. 118(9) 3557-3578.

Samadi S, Carbone G J, Mahdavi M, Sharifi F and Bihamta M R 2012 Statistical downscaling of climate data to estimate streamflow in a semi-arid catchment; Hydrol. Earth Syst. Sci. Discuss. 9 4869-4918.

Samadi S, Carbone G, Mahdavi M, Sharifi F and Bihamta M R 2013 Statistical downscaling of river runoff in a semi-arid catchment; Water Resour. Manag. 27(1) 117136.

Santos M and Fragoso M 2013 Precipitation variability in northern Portugal: Data homogeneity assessment and trends in extreme precipitation indices; Atmos. Res. 131 $34-45$.

Şen Z, Alsheikh A L, Alamoud A S M, Al-Hamid A A, El-Sebaay A S and Abu-Risheh A W 2012 Quadrangle downscaling model and water harvesting in arid regions: Riyadh case; J. Irrig. Drain. Eng. 138(10) 918 923.

Shahid S 2011 Trends in extreme rainfall events of bangladesh; Theoret. Appl. Climatol. 104(3-4) 489-499.

Sohn S J, Ahn J B and Tam C Y 2013 Six month-lead downscaling prediction of winter to spring drought in South Korea based on a multimodel ensemble; Geophys. Res. Lett. 40(3) 579-583.

Souvignet M and Heinrich J 2011 Statistical downscaling in the arid central Andes: Uncertainty analysis of multimodel simulated temperature and precipitation; Theoret. Appl. Climatol. 106(1-2) 229-244.

Su B D, Jiang T and Jin W B 2006 Recent trends in observed temperature and precipitation extremes in the Yangtze River basin, China; Theor. Appl. Climatol. 83 139-151.

Syed F S, Iqbal W, Syed A and Rasul G 2014 Uncertainties in the regional climate models simulations of South-
Asian summer monsoon and climate change; Clim. Dyn. 42(7-8) 2079-2097.

Tareghian R and Rasmussen P F 2013 Statistical downscaling of precipitation using quantile regression; J. Hydrol. $487122-135$.

Tripathi S, Srinivas V V and Nanjundiah R S 2006 Downscaling of precipitation for climate change scenarios: A support vector machine approach; J. Hydrol. 330(3-4) 621-640.

Tsidu G M 2012 High-resolution monthly rainfall database for ethiopia: Homogenization, reconstruction, and gridding; J. Climate 25(24) 8422-8443.

Valle S, Li W and Qin S J 1999 Selection of the number of principal components: The variance of the reconstruction error criterion with a comparison to other methods; Ind. Eng. Chem. Res. 38 4389-4401.

Von Storch H 1999 On the use of "inflation" in statistical downscaling; J. Climate 12(12) 3505-3506.

Wang X J, Zhang J Y, Shahid S, Guan E H, Wu Y X, Gao J and He R M 2014 Adaptation to climate change impacts on water demand; Mitigation and Adaptation Strategies for Global Change, doi: 10.1007/s11027-014-9571-6.

Wang X J, Zhang J Y and Yang Z F 2013 Historic water consumptions and future management strategies for Haihe River basin of northern China; Mitigation and Adaptation Strategies for Global Change, doi: 10.1007/s11027-013-9496-5.

Wetterhall F, Bárdossy A, Chen D, Halldin S and Xu C Y 2006 Daily precipitation-downscaling techniques in three Chinese regions; Water Resour. Res. 42(11) W11423.

Wilby R 1998 Statistical downscaling of daily precipitation using daily airflow and seasonal teleconnection indices; Clim. Res. 10(3) 163-178.

Wilby R L, Dawson C W and Barrow E M 2002 SDSM - a decision support tool for the assessment of regional climate change impacts; Environmental Modelling $\&$ Software 17(2) 145-157.

Wilby R, Charles S, Zorita E, Timbal B, Whetton P and Mearns L 2004 Guidelines for use of climate scenarios developed from statistical downscaling methods; www. ipcc-data.org/guidelines/dgm_no2_v1_09_2004.pdf.

Zhang L, Ma Z M and Kang S Z 2008 Analysis of impacts of climate variability and human activity on stream flow for a river basin in arid region of northwest China; J. Hydrol. 352 239-249. 